\title{
An Experimental Investigation to Study the Performance and Emission Characteristics of Chicken Fat Oil Fuelled DI Diesel Engine
}

\author{
P. Lakshmanan ${ }^{1}$, P. Kaliyappan ${ }^{2}$, M. Ranjithkumar ${ }^{1}$, K. Aravinth ${ }^{1}$, D. Vakkachan ${ }^{1}$, \\ C. Moorthy ${ }^{2}$ and S. Kumar ${ }^{2}$ \\ ${ }^{1}$ Department of Mechanical Engineering, K. Ramakrishnan College of Technology. \\ ${ }^{2}$ University College of Engineering, Villupuram, India \\ †Corresponding Author Email: pandiyan.lakshmanan1@gmail.com
}

(Received February 16, 2017; accepted July 30, 2017)

\begin{abstract}
The importance of biodiesel as a renewable and economically available alternative to fossil fuel for applications in Compression Ignition (CI) engines has led to intense research in the field over the last two decades. This is predominantly due to the depletion of petroleum resources and increasing awareness of environmental and health impacts from the combustion of fossil fuel. Biodiesel is favored over other biofuels because of its compatibility with present day CI engines, with no further adjustments required to the core engine. Such as carbon monoxide, Sulphur oxides, unburnt hydrocarbons and particulate matters are potentially reduced. The effects of biodiesel on nitrogen oxides emission require further tests and validations. The improvement in most of the diesel emission species comes with a trade-off in a reduction of brake power and an increase in fuel consumption. The outcomes completely corroborate the assumption which claims that adding biodiesel to conventional diesel fuel has a strong influence on lowering $\mathrm{CO}_{2}, \mathrm{CO}, \mathrm{HC}$, Oxides of Nitrogen and smoke.
\end{abstract}

Keywords: Compression Ignition engine; Carbon dioxide; Carbon monoxide and Hydrocarbon.

\section{INTRODUCTION}

\subsection{Internal Combustion Engine}

An engine is a device which transforms one form of energy in to another form. However, while transforming energy from one to another the efficiency of conversion plays an important role. Normally most of the engine converts thermal energy into mechanical work and therefore they are called heat engine. Heat engine is a device which transforms the chemical energy of the fuel into thermal energy and utilizes this thermal energy to perform useful work. Heat engine classified into two categories: (i) Internal Combustion Engine (IC Engines), (ii) External Combustion Engine (EC Engines).

Engine whether Internal Combustion or External Combustion are of two Types, (i) Rotary Engine, (ii) Reciprocating Engine .The most widely used once are reciprocating internal combustion engine, The gas turbine engine and the steam engine. the steam engine rarely used now a days the reciprocating internal combustion engine have more advantages over the steam engine due to the absence of heat exchanger in the passage of working fluid .In Internal Combustion engine higher thermal efficiency can be obtained with moderate max working presser of the fluid in the cycle, and therefore, the weight to power ratio is less than that of steam turbine plant. Also, it has been possible to develop reciprocating internal combustion engines of very small power output with reasonable thermal efficiency and cost.The application of IC engine includes the automobile industry, power plants, and reciprocating components used in heavy machine and factories.

\subsection{Alternative Fuels}

Day -to-day, the fuel economy of engines is getting improved and will continue to improve. However the enormous increase in number of vehicles has been meeting the current demand for fuel. Gasoline and diesel will become scarce and more costly in the future. With the increased use and depletion of fossil fuels, alternative fuel technology will become in the coming decades By motivating the development of 


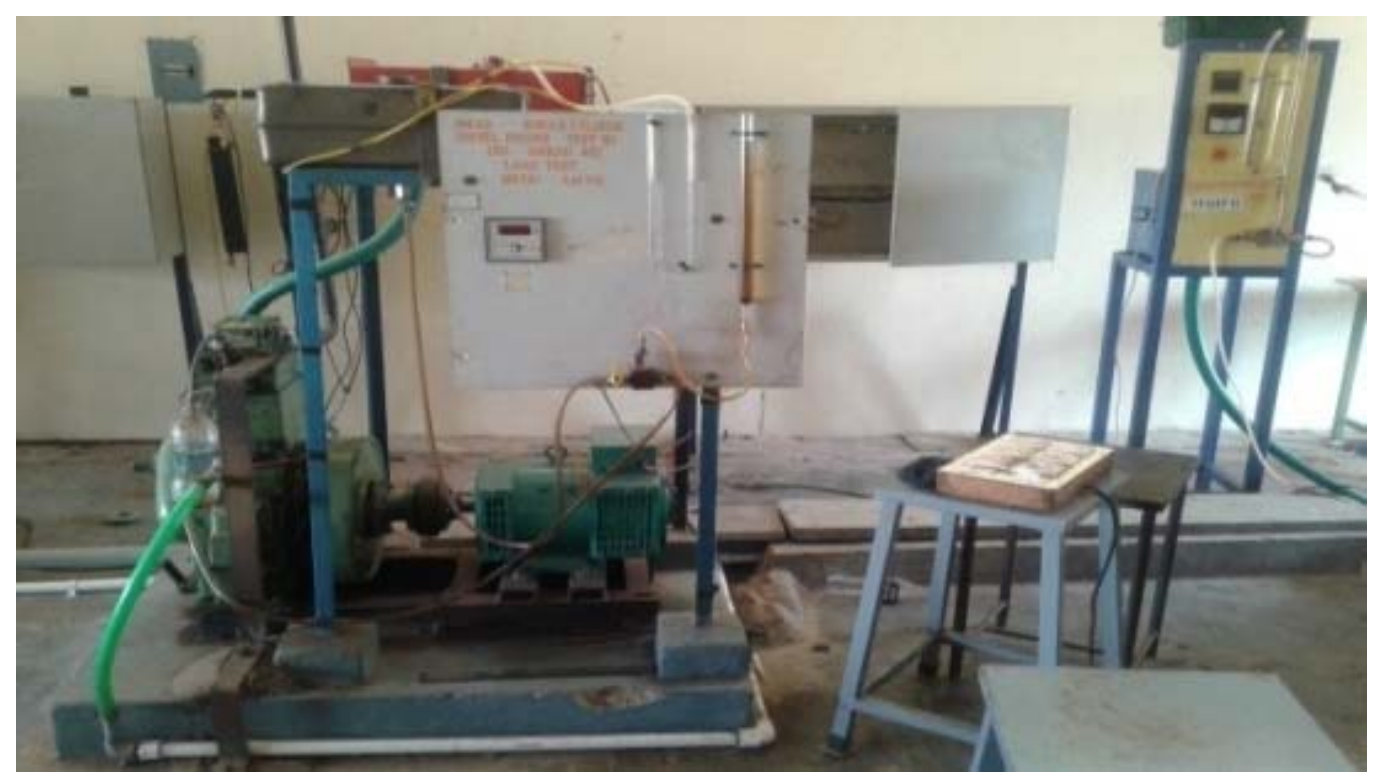

Fig. 1. Experimental Setup.

Li et al. (2105) motivated the development of alternate fuels for the IC engines is the concern over the emission problems of gasoline and diesel engine. Combined with other air pollutant system, the large number of automobiles is major contributor to the air quality problems of the world.

Singh et al. (2009) surveyed the amount of alternate fuel being used in automobiles. One of the reason for developing the alternate fuel technology is the fact that a large percentage of crude oil must be imported from various countries which control the larger oil fields. Now many of the automobiles has been used alternative fuels in limited qualities. This paves the way for comparison with similar diesel -fuelled vehicles, and simplify fuelling of these vehicles.

The engines used for alternative fuels are modify engine which are originally designed for diesel fuelling. Only when extensive research and development is done over the period, mostly the performance and efficiency can be realized from these engines. Sakthivel et al. (2016) conducted performance test and emission test on diesel engine by blending fish oil with diesel. The importance of biodiesel as a renewable and economically available alternative to fossil fuel for applications in Compression Ignition (CI) engines has led to intense research in the field over the last two decades. This is predominantly due to the depletion of petroleum resources and increasing awareness of environmental and health impacts from the combustion of fossil fuel.

\section{METHODOLOGY}

\subsection{Experimental Procedure}

Engine performance and emissions have been tested in Diesel Engine. A trademark RAINBOW-LA186, single-cylinder, four-stroke, with speed variation, aircooled and direct-injection diesel engine is used for tests. Schematic view of experimental test apparatus is shown in Fig. 1. Ranger ST-4 brand laser thermometer is used for the measurement of exhaust gas temperature. After the engine is started, the engine temperature reaches the regime temperature using diesel fuel (D2) where the experiments are based on 1000 and $2500 \mathrm{rpm}$ in the range of $500 \mathrm{rpm}$ intervals. Then, instead of diesel fuel, a mixture of fuels is sent to the engine separately, and experiments are repeated.. Gas analyzer of CAPELEC CAP-3200 is used to measure emissions exhausted from the test engine. The analyzer measures carbon monoxide (CO), hydrocarbon (HC), carbon dioxide (CO2) and nitrogen dioxide $(\mathrm{NOx})$. After the engine has reached the operation temperature, the probe of the device is placed in the exhaust pipe. Then, the emissions values are measured by the device were printed out through a printer on the device.

\subsection{Transesterification Process}

It is the process where renewable resources like animal fats and vegetable oils could be transformed chemically to clean-burning biodiesel. It was believed before, that vegetable oils can be directly used without the need for any preparation or processing. Sarveshwar Reddy et al. (2016) \& Atul Dhar et al. (2014) investigated and identified that residues and deposits from combustion would create some problems in piston rings, fuel injectors, and oil performance.

Through a process of mixing the oils with ethanol or methanol, a reaction called esters are formed as shown in the Fig.2 Esters are relatively insoluble in water. They have this tendency to form a tiny layer in the surface of the water. So water is not a good base for this process. The best tool for the job is acid. The result is the esterified edition of vegetable oil (Dhar \& Agarwal 2014) or the esterification biodiesel product. 


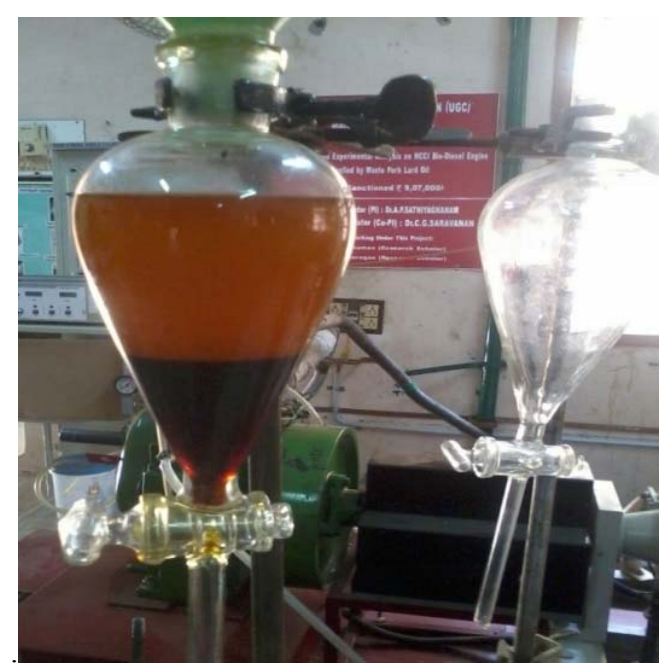

Fig. 2. Esterification Process.

\subsection{Transesterification Procedure}

Transestrification has been carried out as done by Asakuma et al. (2013).

\section{Step 1}

Taking 15-20gms of potassium hydroxide $(\mathrm{KOH})$ pellets.

\section{Step 2}

Then dissolved in $50 \mathrm{ml}$ of methanol solution with $10 \mathrm{ml}$ of sulphuric acid as a catalyst to produce fast reaction with solution.

\section{Step 3}

Then the dissolved solution is mixed with $1 \mathrm{~L}$ of chicken fat oil by means of stirrer.

\section{Step 4}

The oil is heated up to $65 \mathrm{C}$ in a beaker. Then the heated oil is agitated using an agitator (stirrer) at 600rpm for 1 hour.

\section{Step 5}

After that the oil is allowed to rest under atmospheric condition for 24 hours in conical flask.

\section{Step 6}

The sediments settle down at the lowest part while the water and oil form separate regions above the oil.

\section{Step 7}

The sediment is removed and the oil and water mixture is heated at $100 \mathrm{C}$ to evaporate the remaining water. After the evaporation process the remaining oil is obtained, which is used as biodiesel.

\subsection{Esterification and Transestricfication Process}

Esterification is the process that utilizes an acid that can alter the FFA (free fatty acids) chains far from the molecule of glycerol, thereby allowing methanol to stick to them and develop into biodiesel.
Transesterification process is the method that utilizes a base compound as the important catalyst to split the FFA chains from the molecule of glycerol then let methanol thereby allowing methanol to stick to them to create biodiesel. The esterification process uses sulfuric acid and it is also called as the Acid method. Transesterification process uses Potassium Hydroxide or Sodium Hydroxide. It is referred to as the Base method. Transesterification process is shown in Fig. 4 When chemical structures of FOME and CFME are examined it could be clearly seen that they contained $31.11,27.74 \mathrm{wt} \%$ saturated free fatty acids, 53.76, $70.68 \mathrm{wt} \%$ unsaturated free fatty, respectively, Oleic acid (C18:1), palmitic acid (C16:0) and docosahexa-enoic acid (C22:6) were the three major components of FOME and CFME. Hossain et al. (2013) \& E. Rajasekar et al. (2014) identified that oleic acid oils are good for oxidation resistance, these oils have caused rise to the fore as an alternative fuel for diesel engines. Oils that contain fatty acids having single, double bonds are alternative oils for diesel engines; however, cetane number will be adversely affected with increasing unsaturation degree of fatty acid (Rajasekar \& Selvi, 2014). The high saturated fatty acids result in biodiesel with a high cetane number. The higher cetane number of biodiesel have many advantages, such as shorter ignition delay, lower NOx emissions, good combustion characteristics, and lesser occurrence of knocking phenomena in combustion process. The cetane number of FOME and CFME is higher than D2 fuel that shows FOB20 and CFB20 blend fuels should be used as an alternative fuel in diesel engines compared to D2 fuel.

\subsection{Production of Waste Oil Methyl Esters and Their Blends}

Using waste oils in biodiesel production is extremely important because it provides recycling and eliminating waste that it threatens environment and human health. Biodiesel is a fuel that has biodegradable and renewable degradation able structure. It is not toxic, carcinogen, and allergic. It provides very good lubrication. It can be used in all kinds of diesel-powered vehicles and also used for heating purposes. Nitin M et al. (2016) pointed the fact that biodiesel has better properties than petroleum diesel; as it is renewable, biodegradable, non-toxic, and essentially free of sulfur and aromatics. Biodiesel seems to be a realistic fuel for future; it has become more attractive recently because of its environmental benefits. Abhishek Sharma et al. (2015) experimentally proved that biodiesel is an eco-friendly fuel. It can be used in any diesel engine without modification. It is only possible to use waste oils or fats as fuels in internal combustion engines either by improving fuel properties or making changes in engine structure. However, Tesfa et al. (2013) showed the needed changes are in the category of injection pressure and timing. It is recommended that remove the fatty acid will decrease the viscosity of fuel oil. In order to reduce the viscosity of the oil/ fat, fish oil and chicken fat methyl esters are produced by using a chemical method which is called as transesterification method. In a study, it is specified 
that the optimum operating parameters for biodiesel conversion process are provided by reducing the FFA of chicken fat. Hence, before it is subjected to basic catalyst in transesterification process FFA is reduced with pre-improvement process by an $\mathrm{H}_{2} \mathrm{SO}_{4}$ catalyst.
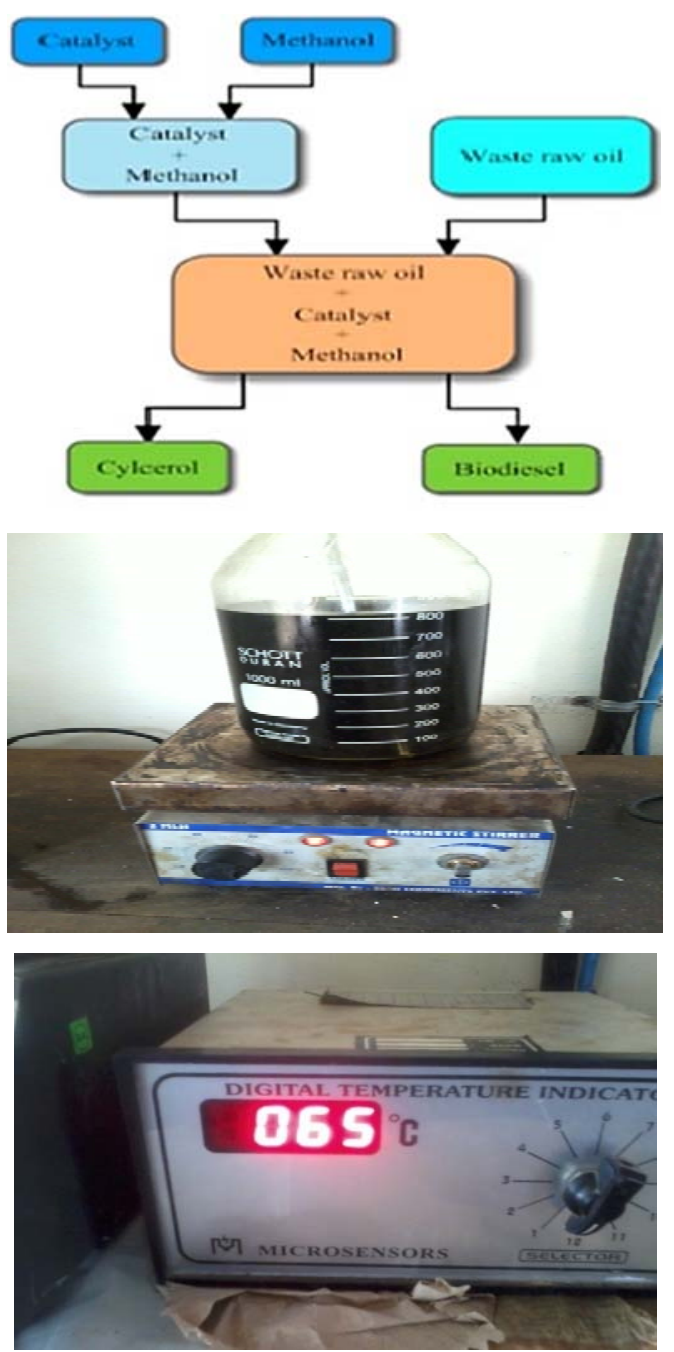

Fig. 3. Biodiesel production stages.

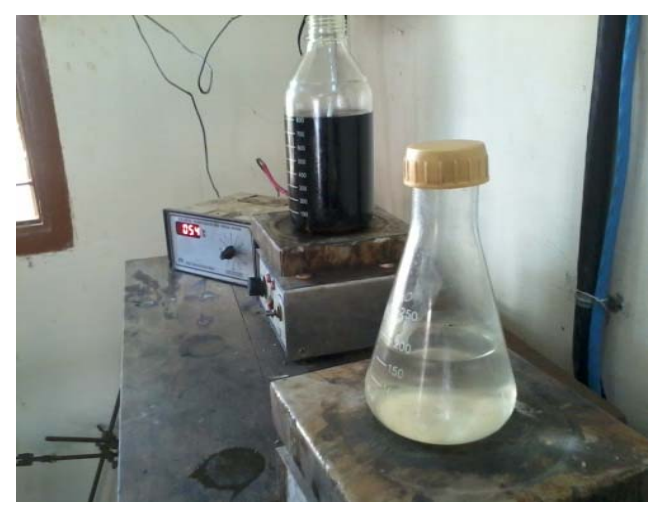

Fig. 4. Transesterification Process.

The production process of oil methyl esters is carried out in stages as indicated in a schematic way in Fig. 4. The concentration of $\mathrm{H}_{2} \mathrm{SO}_{4}$ was $2 \%$ volumetrically for CFME production in order to reduce FFA content of chicken fat below $1 \%$. of $\mathrm{H}_{2} \mathrm{SO}_{4}$ was $2 \%$ volumetrically for CFME production in order to reduce FFA content of chicken fat below $1 \%$. Waste anchovy fish oil and waste chicken fat biodiesel production steps have been outlined as follows: (i) Presence of water in waste oil causes saponification, depletion of the catalyst and reduction in catalyst efficiency. Therefore, waste oil is put in an open mouth beaker at different times and is heated up to $1101 \mathrm{C}$ in order to evaporate the water in the oil, and it is to be cooled to $601 \mathrm{C}$ in room temperature. (ii) The mixture of both fish oil and chicken oils are stirred in magnetic stirrer for $2 \mathrm{~h}$ at temperature of $601 \mathrm{C}$. To prevent loss of alcohol during reaction, a wet cloth is kept on top of reaction vessel. (iii) At the end of the reaction phase of the separation of ester and glycerol, the mixture is stored at room temperature for $8 \mathrm{~h}$. At the end of this period, Glycerol and ester phases are separated from each other and glycerin is taken into separation hopper. Obtained biodiesel is filtered through cloth filters and washing process is taken up. (iv) For the possibility of water in the biodiesel in separation funnel, the water is heated above the boiling point of $1001 \mathrm{C}$ and to make it evaporate. As a result, lower viscosity methyl esters (FOME and CFME) are obtained.

\section{RESULTS AND DISCUSSION}

\subsection{Performance Results}

The performance tests were conducted with the various blend properties of Diesel-chicken fat oil fuels. The performance parameter such as Brake power, Brake Thermal Efficiency, Indicated power, Friction power, Total fuel consumption with the base diesel fuel and performance of the blended Chicken fat oil-Diesel Fuel was analyzed.

\subsubsection{Brake Thermal Efficiency}

The performance of the Diesel-Chicken fat oil blends was calculated by relating the Brake power to input Load in terms of percentage as said by Akash Deep et al. (2017). 2017). The fuel consumptions was determined by the time of consumption of fuel for 10 CC. Fig. 5 shows the variation in brake thermal efficiency for the different proportion of DieselChicken fat oil blends in a direct injection Diesel engine.

\subsubsection{Mechanical Efficiency}

The mechanical efficiency of the Diesel-Chicken fat oil blends was calculated by relating the brake power to Heat input. The output power is calculated with the current given to the field for stator the electromagnets. The Fig. 6 shows the variation in mechanical efficiency for the different proportion of Diesel-Chicken fat oil blends in a direct injection Diesel engine.

The mechanical efficiency of the engine fuelled with $\mathrm{B} 20$ is higher than the other blends. 
BRAKE THERMAL EFFICIENCY

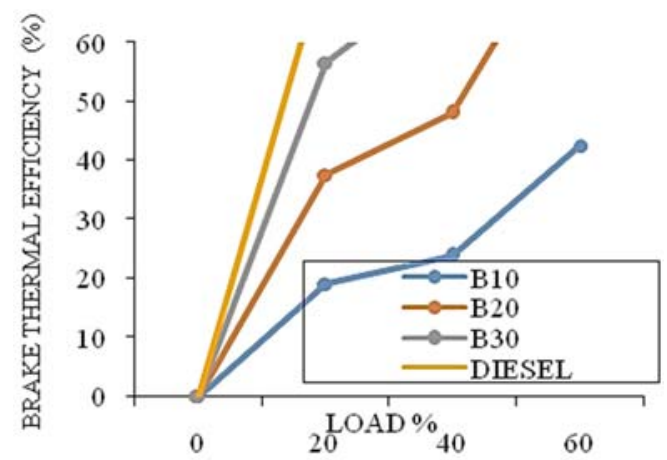

Fig. 5. Load Vs. Brake thermal efficiency.

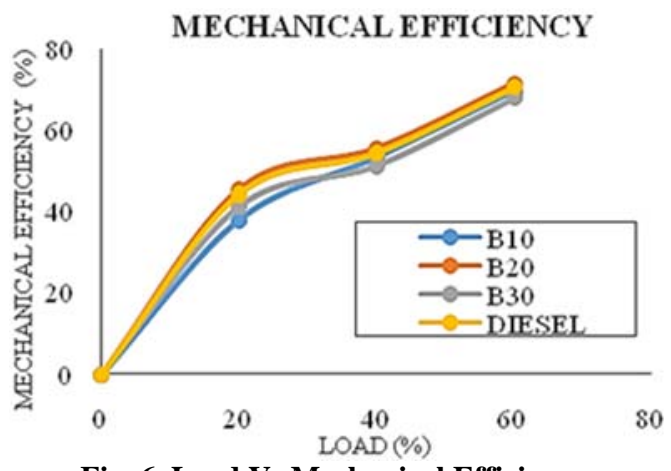

Fig. 6. Load Vs Mechanical Efficiency.

\subsubsection{Total Fuel Consumption}

The Total Fuel Consumption of the Diesel-chicken oil blends was calculated by relating the brake power (output) to Heat input (Fuel power). The output power is calculated with the current given to the field for stator the electromagnets

The fuel power was determined by Fig. 7 shows the variation in Total Fuel Consumption for the different proportion of Diesel-Chicken fat oil blends in a direct injection Diesel engine.

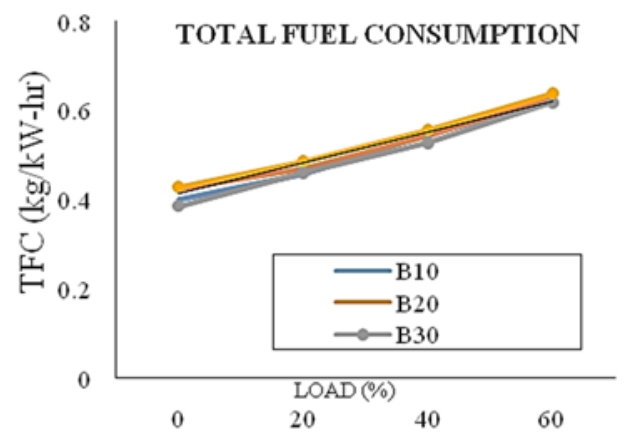

Fig. 7. Load Vs Total fuel consumption.

\subsection{Emission Characteristics}

The exhaust gas emission test at different loading condition for the various blending ratio DieselChicken fat oil fuels are examined with the help of AVL DI gas analyzer.

\subsubsection{Carbon Monoxide Emissions}

When there is not enough oxygen to convert all carbon to $\mathrm{CO}_{2}$, some fuels does not burned and some carbon ends up as $\mathrm{CO}$. Because of using oxygenated fuel it reduces the $\mathrm{CO}$ emissions in the blending. Fig. 8shows the $\mathrm{CO}$ emission level for various loading condition of the engine the different proportion of chicken oil in the diesel fuel.

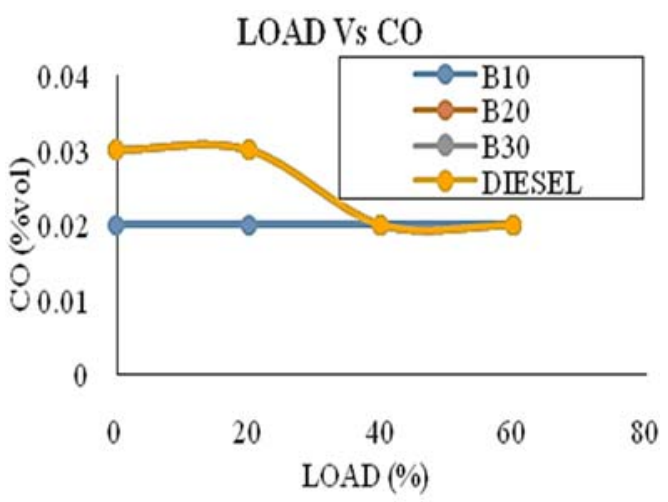

Fig. 8. CO emission of the Blended Fuels.

\subsubsection{Carbon Dioxide Emissions}

The graphs are plotted between different loads of the engine to the emissions of carbon di oxide (CO2) in the Fig.9 For the higher blending ratio the $\mathrm{CO}$ emission is slight increase due to the nonhomogeneity of fuel-air mixture will lead for lean mixture to combust properly.

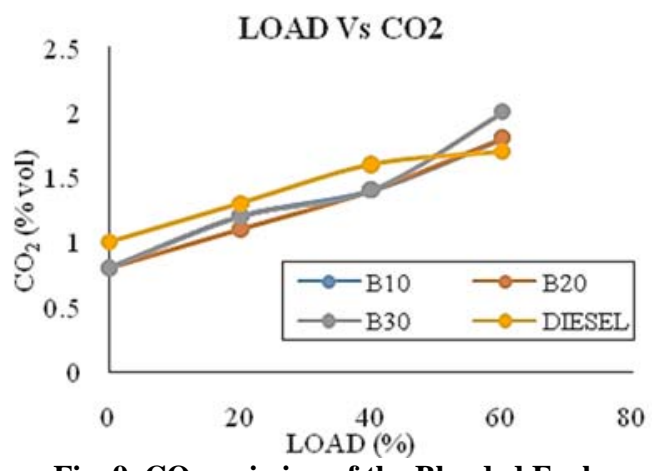

Fig. 9. $\mathrm{CO}_{2}$ emission of the Blended Fuels.

\subsubsection{Hydrocarbon Emission}

The Hydrocarbon emission of the different blends was tested with various load condition of the engine. Fig. 10. shows the variation in the emission level of the hydrocarbon for the addition of chicken oil in the diesel fuel. According to Hyun Gu Roh et al. (2014) for higher blending ratio, a slight increase in the emission level of $\mathrm{HC}$ is observed due to the nonhomogeneity of fuel-air mixture. The homogeneity will lead to lean mixture formation and combusts properly. Hydrocarbon (HC) emissions occur in regions consisting of non-complete combustion. $\mathrm{HC}$ emissions are not directly related to the engine load 
and speed. It more depends on the geometry of the injection system and combustion chamber. When the amount of air breathing capacity of engine is increased the oxygen content in the chamber is also increased. This will reduce the amount of unburnt hydrocarbon emitted. Hydrocarbons also contain awide variety of organic chemical substances, and they do not have the toxic effect in the normal atmospheric conditions. However, Ashok et al. (2016) found the reactions of other exhaust species combined with the air can cause considerable pollution. There are significant increases in the amounts of hydrocarbons in areas with high motor vehicle traffic volumes (Ashok et al. 2016). The exhaust emissions of unburned $\mathrm{HC}$ are shown with respect to a different number of revolutions at full load. As shown in the figure, unburned $\mathrm{HC}$ emissions of blend fuels (FOB20 and CFB20) are lower than D2 fuel. When compared with D2 fuels, the amount of decrease in hydrocarbon emissions is found to be $12.89 \%$. This amount is very important in the point of thermal performance of the engine. The higher HC is exhausted in emissions, the lower engine performance is obtained from an engine.

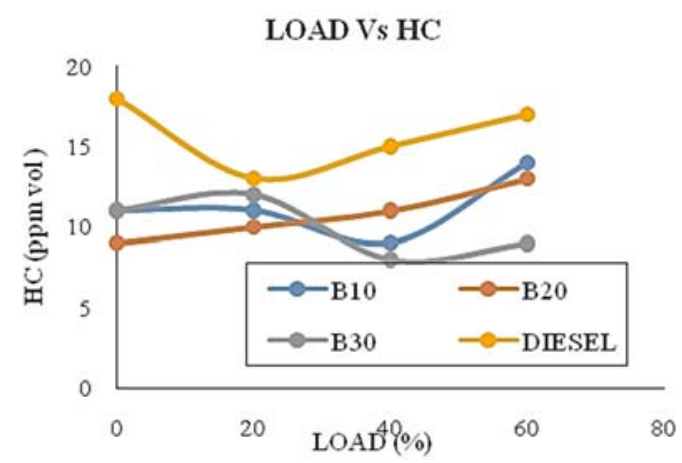

Fig. 10. HC emission of the Blended Fuels.

\subsubsection{Oxides of Nitrogen Emissions}

The Oxides of Nitrogen are exhaust due to the presence of nitrogen in the Air used for the combustion. In this emission characteristics of the blended chicken oil fuel for the Diesel are plotted below in Fig. 11 Two important parameters that influence the formation of NOx are combustion chamber temperature and air-fuel ratio. When the combustion chamber temperature increases above $1800 \mathrm{~K}$, nitrogen and oxygen are chemically combined in the air and becomes nitrogen oxides which are harmful for human health and environment. Nitrogen oxides combine with moisture in the lungs by forming nitric acid and lead to a respiratory disease. As a result, diluting the mixture with exhaust gases in the combustion chamber causes to reduce both the combustion temperatures and the amount of NOx produced. As per Alessandro et al. (2016), nitrogen affinity with oxygen at high temperature increases the emissions of NOx rapidly. Nitrogen oxides are among the gasses in greenhouse gases that threaten human health. Therefore, nitrogen oxides are requested to be as little as possible in the air. Nitrogen oxide formation in diesel engines depends on injected fuel quantity, injection time, the amount of air taken into the cylinder and temperature By addition of chicken fat oil to diesel fuel decrease the content of carbon and hydrogen in the blend solutions. This provides an additional beneficiary effect of reducing the NOx emission as shown in Fig 11.

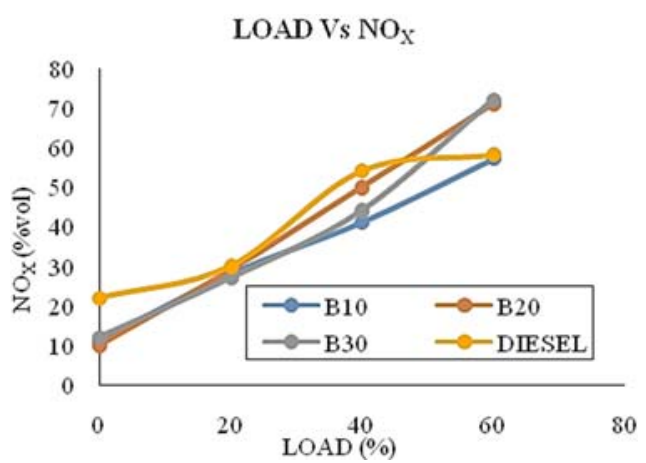

Fig. 11. NOX Emission of the Blended Fuels.

\section{CONCLUSION}

When the interest of creating a new fuel blend in the automobile field, the preparation of diesel- Chicken fat oil has been done as fish oil was successfully utilized in DI-Diesel engine. The performance of DIDIESEL engine with the blended fuels has been increased and also the emission test results have been given and new hope to use these kind of fuel to the society for creating an eco-friendly environment. From this paper, It is concluded that for higher blended fuels the Brake thermal efficiency the maximum at low loading condition. For producing high brake power the total fuel consumption is relatively low. The $\mathrm{CO}$ emission at maximum loading condition is lower for higher blended fuel. By using this alternative fuel the complete combustion can be achieved easily.

\section{REFERENCES}

Asakuma, K. A. K., P. J. Pomonis, G. Manos and M. G. Kontominas (2013). Transesterification of rapeseed oil for the production of biodiesel using homogeneous and heterogeneous catalysis. Fuel Process Technol 90, 1016-1022.

Ashok, B., K. Nanthagopal, R. Thundil Karuppa Raj, J. Pradeep Bhasker and D. Sakthi Vignesh (2017). Influence of injection timing and exhaust gas recirculation of a Calophyllum inophyllum methyl ester fuelled CI engine. Fuel Processing Technology 16, 18-30.

D’Alessandro, B., G. Bidini, M. Zampilli, P. Laranci, P. Bartocci and F. Fantozzi (2016). Straight and waste vegetable oil in engines: Review and experimental measurement of emissions, fuel consumption and injector fouling on aturbocharged commercial engine Fuel 182, 198-209.

Deep, A., S. Singh Sandhu, S. C. A. Deep, S. S. 
Sandhu and S. Chander (2017). Experimental investigations on the influence of fuel injection timing and pressure on single cylinder C.I. engine fueled with $20 \%$ blend of castor biodiesel in diesel. Fuel 210, s15-22.

Dhar, A., A. Kumar Agarwal (2014). Performance, emissions and combustion characteristics of Karanja biodiesel in a transportation engine. Fuel 119, 70-80.

Dhar, A., A. Kumar Agarwal (2014). Performance, emissions and combustion characteristics of Karanja biodiesel in a transportation engine. Fuel 119, 70-80.

Gnanasekaran, S., N. Saravanan, M. Ilangkumaran (2016). Influence of injection timing on performance, emission and combustion characteristics of a DI diesel engine running on fish oil biodiesel. Energy 116, 1218-1229.

Hossain, A. K., M. Ouadi, S. U. Siddiqui, Y. Yang, J. Brammer, A. Hornung, M. Kay and P. A. Davies (2013). Experimental investigation of performance, emission and combustion characteristics of an indirect injection multicylinder CI engine fuelled by blends of deinking sludge pyrolysis oil with biodiesel. Fuel 105,135-142.

Li, J., W. M. Yang, H. An and D. Zhao (2015). Effects of fuel ratio and injection timing on gasoline/biodiesel fueled RCCI engine: A modeling study. Applied Energy 155.

Rajasekar, E. and S. Selvi (2014). Review of combustion characteristics of CI engines fueled with biodiesel. Renewable and Sustainable Energy Reviews 35,390-399.

Roh, H. G., D. Lee and C. Sik Lee (2014). Impact of DME-biodiesel, diesel-biodiesel and diesel fuels on the combustion and emission reduction characteristics of a CI engine according to pilot and single injection strategies. Journal of the Energy Institute $x x x, 1-10$.

Sakhare, N. M., P. S. Shelke and S. Lahane (2016). Experimental Investigation of Effect of Exhaust Gas Recirculation and Cottonseed B20 Biodiesel Fuel on Diesel Engine. Procedia Technology 25, $869-876$.

Sarveshwar Reddy, M., N. Sharma, A. Kumar Agarwal (2016). Effect of straight vegetable oil blends and biodiesel blends on wear of mechanical fuel injection equipment of a constant speed diesel engine. Renewable Energy 99, 1008e1018.

Sharma, A. and S. Murugan (2015). Potential for using a tyre pyrolysis oil-biodiesel blend in a diesel engine at different compression ratios. Energy Conversion and Management 93, 289297.

Singh, B. and Y. C. Sharma (2009). Development of biodiesel: current scenario. Renew Sustain Energy Rev 13, 1646-1651.

Tesfa, A. D. B., F. Gu, R. Mishra and A. D. Ball (2013). LHV predication models and LHV effect on the performance of CI engine running with biodiesel blends. Energy Conversion and Management 71,217-226. 